\title{
Candida-Related Immune Response Inflammatory Syndrome Treated with Adjuvant Corticosteroids and Review of the Pediatric Literature
}

\author{
Adjuvan Kortikosteroid ile Tedavi Edilen Candida-Ilişkili Immün Yanıt Enflamatuvar Sendromu \\ ve Pediatrik Literatür Derlemesi
}

Dildar Bahar Genç1, Sema Vural1, Nafiye Urgancl2, Tuğçe Kurtaraner3, Nazan Dalgıç4
1Şişli Hamidiye Etfal Training and Research Hospital, Clinic of Pediatric Oncology, İstanbul, Turkey
2Şişli Hamidiye Etfal Training and Research Hospital, Clinic of Pediatric Gastroenterology, Istanbul, Turkey
3Şişli Hamidiye Etfal Training and Research Hospital, Clinic of Pediatrics, Istanbul, Turkey
${ }^{4}$ Şişli Hamidiye Etfal Training and Research Hospital, Clinic of Pediatric Infectious Disease, istanbul, Turkey

To the Editor,

Chronic disseminated candidiasis (CDC) is a potentially fatal complication observed in febrile neutropenia [1]. The diagnosis is usually made after neutrophil recovery and microbiological proof has been often negative [2]. Granulomatous histopathology, radiological lesions coincident with resolution of granulocytopenia, and rapid response to corticosteroids favors immune-mediated pathogenesis. Recently, CDC has been suggested to be related to Immune response inflammatory syndrome (IRIS), an exacerbated response to a preexisting antigenic stimulus in patients with rapid immune restoration $[1,3]$. IRIS has been mostly documented in HIV-infected patients with immune recovery after antiretroviral therapy [4]. Here, we present a case of Candida-related IRIS and review the current literature on children.

A male, aged 6 years and 7 months, with B-cell acute lymphoblastic leukemia was treated for presumed typhlitis with meropenem, teicoplanin, and amphotericin B during induction

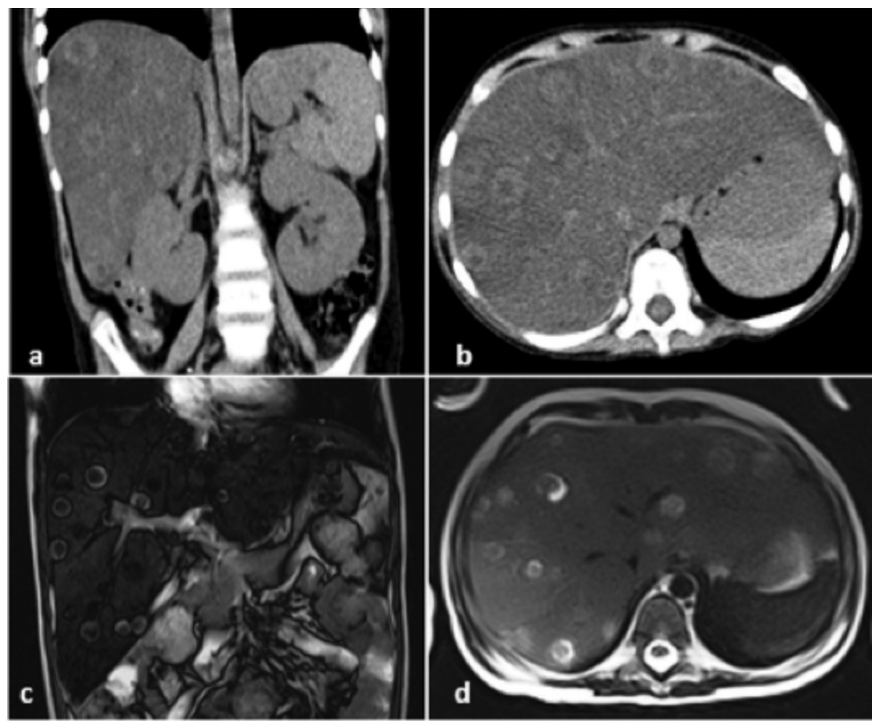

Figure 1. Coronal and axial computed tomography images $(a, b)$; coronal and axial magnetic resonance images of circumscribed typical hepatic Candida lesions (c, d). therapy. Thoracoabdominal CT scans revealed hepatosteatosis/ hepatomegaly. Fever subsided on the $2^{\text {nd }}$ day. During steroid tapering and on the 8th day of antibiotics, the patient developed fever and abdominal pain with marked elevation of liver enzymes, predominantly of GGT. Bone marrow examination showed no evidence of blasts or hemophagocytosis and the blood count was normal. Control imaging showed typical widespread hepatic bull's eye lesions (Figure 1). The liver biopsy demonstrated granulomatous inflammation, but no fungus was detectable. According to European Organization for Research and Treatment of Cancer/Mycoses Study Group criteria, the diagnosis was possible invasive fungal infection, most likely candidiasis. Reappearance of symptoms after neutrophil recovery indicated IRIS. We empirically administered dexamethasone for 14 days. Fever disappeared after $24 \mathrm{~h}$ and liver function tests improved in 1 week. He was discharged with oral voriconazole. During vincristine therapy, voriconazole was replaced with amphotericin B to avoid toxicity. In the $13^{\text {th }}$ month of voriconazole, the liver lesions showed partial regression and calcification. As re-biopsy was negative for microorganisms and showed only rare microgranulomas, we stopped the voriconazole. The patient completed chemotherapy and has been without any exacerbation for 32 months since the initial diagnosis of IRIS.

Clinical and/or radiological deterioration after neutrophil recovery is a well-known entity in patients treated for opportunistic infections [4]. The immune system shifts towards Th-1 type response and amplifies proinflammatory cascades [1]. Therefore, the severity of radiological/clinical findings might depend on the immune status of the patient $[5,6]$. IRIS is a diagnosis of exclusion; other possible causes of persistent fever should be evaluated. If the clinical scenario is not consistent with preexisting disease, treatment side effects, or a possible newly acquired pathogen, IRIS deserves diagnostic consideration. In the previous Candidarelated IRIS reports on children with cancer, all patients had fever and liver dysfunction accompanying normal neutrophil counts. Liver biopsies showed granuloma formation. Tissue cultures for fungi were negative in all samples except one. The 


\begin{tabular}{|c|c|c|c|c|c|c|c|c|}
\hline 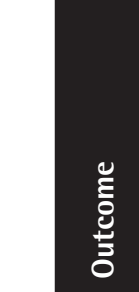 & 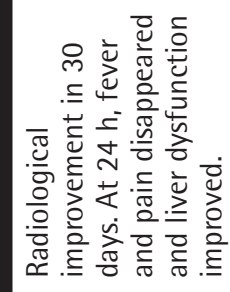 & 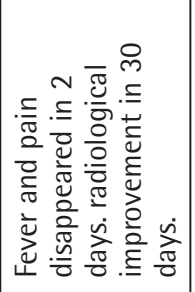 & $*$ & 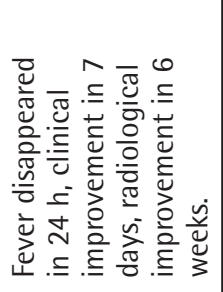 & 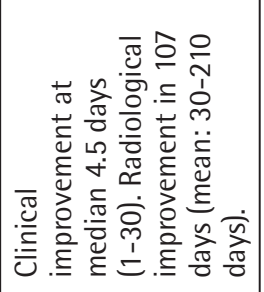 & 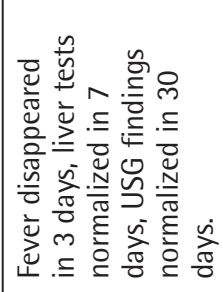 & 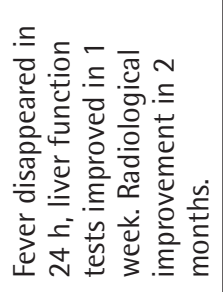 & 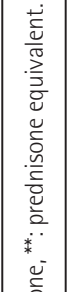 \\
\hline 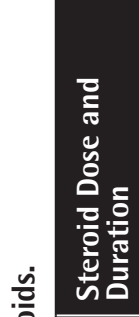 & 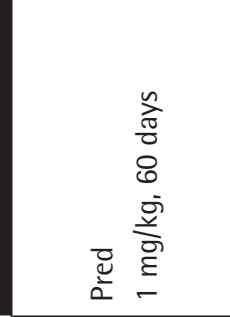 & 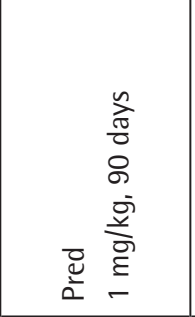 & 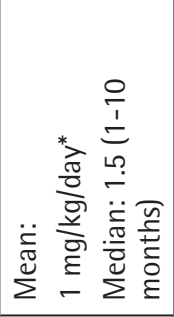 & 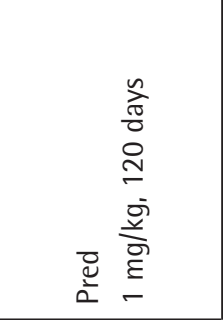 & 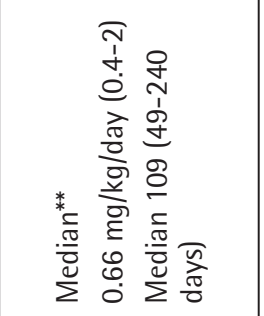 & 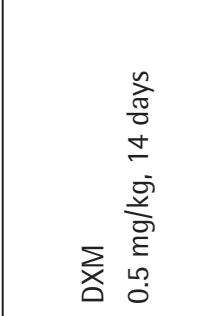 & 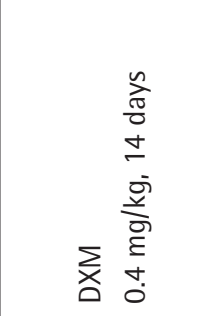 & 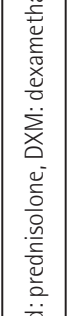 \\
\hline 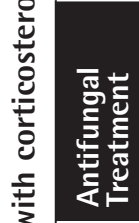 & 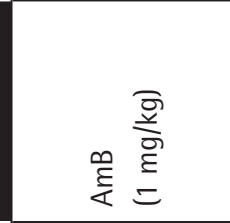 & 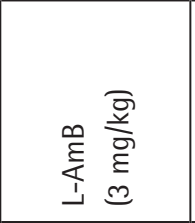 & $*$ & 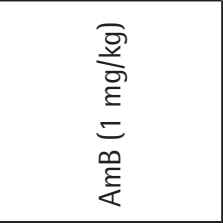 & * & 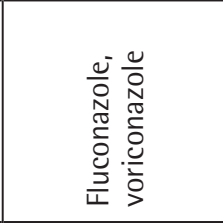 & 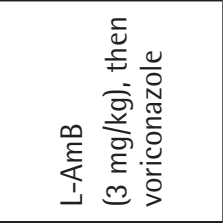 & 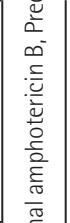 \\
\hline 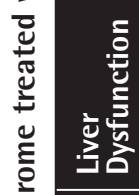 & $\mp$ & $\mp$ & 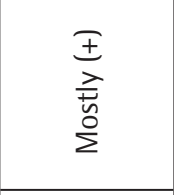 & $\mp$ & $\mp$ & $\mp$ & $\mp$ & 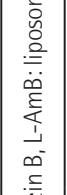 \\
\hline 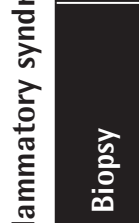 & 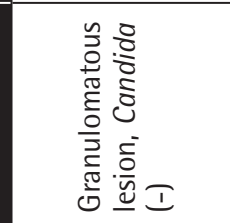 & 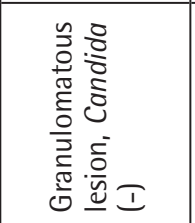 & $\begin{array}{l}\text { 永 } \\
\stackrel{5}{5} \\
\text { s. }\end{array}$ & 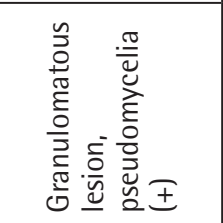 & 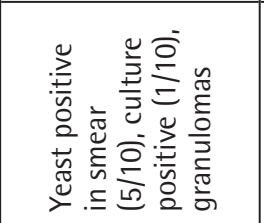 & $I$ & 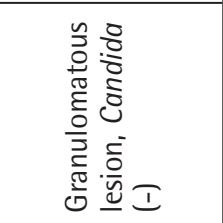 & 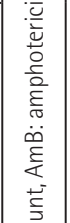 \\
\hline 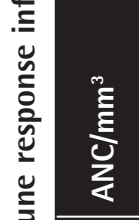 & $\underset{\sim}{\stackrel{\infty}{\sim}}$ & $\begin{array}{l}\stackrel{8}{\circ} \\
\stackrel{\leftrightarrow}{N}\end{array}$ & 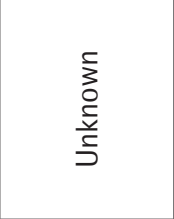 & 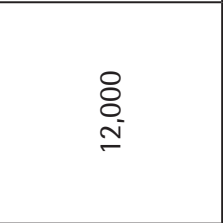 & 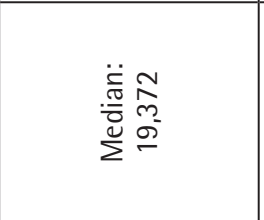 & 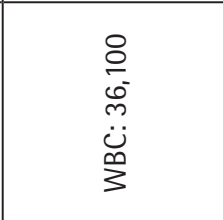 & $\stackrel{\circ}{\stackrel{\circ}{\sim}}$ & 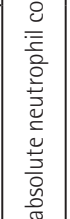 \\
\hline 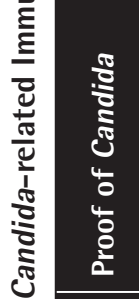 & 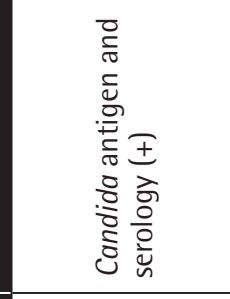 & 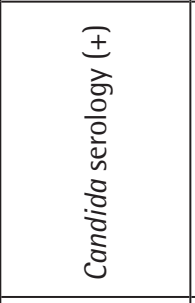 & $*$ & 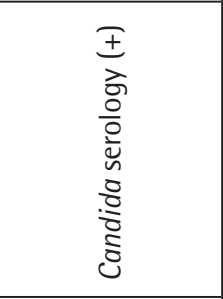 & 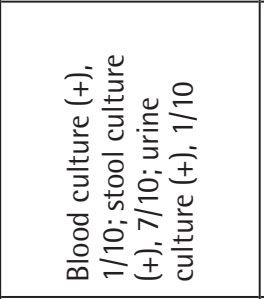 & $I$ & $I$ & 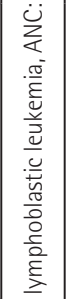 \\
\hline 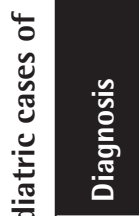 & $\sum_{<}$ & $\vec{\psi}$ & 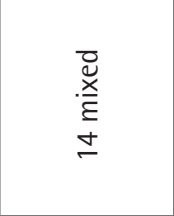 & 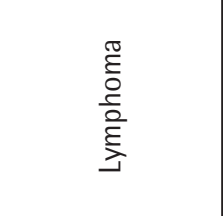 & 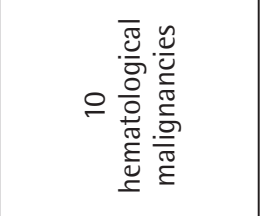 & $\vec{\gtrless}$ & $\vec{\gtrless}$ & 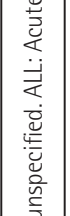 \\
\hline 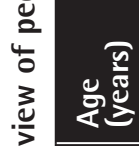 & $\simeq$ & $\infty$ & 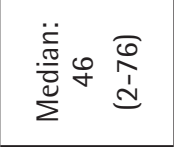 & $\approx$ & 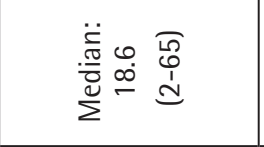 & 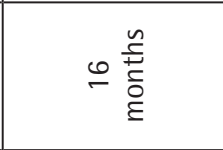 & 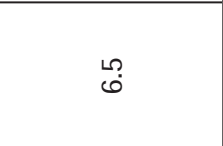 & 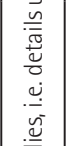 \\
\hline 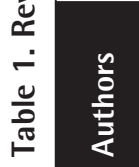 & 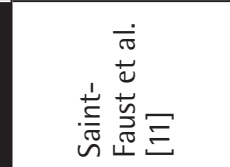 & 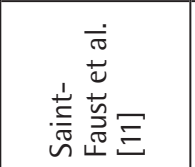 & 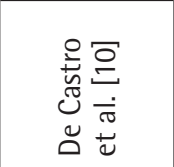 & 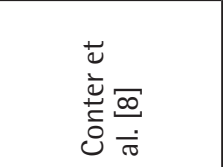 & 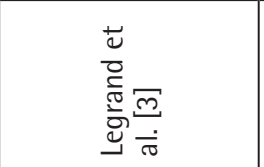 & 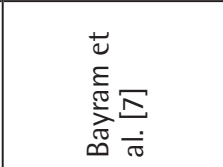 & 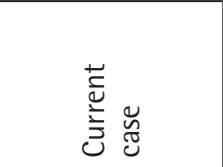 & 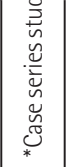 \\
\hline
\end{tabular}


most commonly administered antifungal agent was amphotericin B. Details of steroid therapy and the outcomes are presented in Table $1[3,7,8,9,10,11]$. Increased susceptibility to infection might be a drawback for prolonged corticotherapy. However, neither Candida reactivation nor other new opportunistic infections have been reported [3].

Candida-related IRIS has been rarely reported in children. Early recognition and appropriate management of IRIS might prevent unnecessary diagnostic procedures, antibiotic usage, and chemotherapy delays.

\section{Acknowledgment}

This work was partially presented at the 9th Biennial Childhood Leukemia Symposium, Prague, Czech Republic, 28-29 April 2014.

Keywords: Leukemia, Febrile neutropenia, Candida, Immune response inflammatory syndrome

Anahtar Sözcükler: Lösemi, Febril nötropeni, Candida, İmmün yanıt enflamatuvar sendromu

Conflict of Interest: The authors of this paper have no conflicts of interest, including specific financial interests, relationships, and/ or affiliations relevant to the subject matter or materials included.

\section{References}

1. Rammaert B, Desjardins A, Lortholary 0 . New insights into hepatosplenic candidosis, a manifestation of chronic disseminated candidosis. Mycoses 2012;55:74-84
2. Fleischhacker M, Schulz $\mathrm{S}$, Jöhrens $\mathrm{K}$, von Lilienfeld-Toal M, Held T, Fietze E, Schewe C, Petersen I, Ruhnke M. Diagnosis of chronic disseminated candidosis from liver biopsies by a novel PCR in patients with haematological malignancies. Clin Microbiol Infect 2012;18:1010-1016.

3. Legrand F, Lecuit M, Dupont B, Bellaton E, Huerre M, Rohrlich PS, Lortholary 0 . Adjuvant corticosteroid therapy for chronic disseminated candidiasis. Clin Infect Dis 2008;46:696-702.

4. Manabe YC, Campbell JD, Sydnor E, Moore RD. Immune reconstitution inflammatory syndrome: risk factors and treatment implications. J Acquir Immune Defic Syndr 2007;46:456-462.

5. Karthaus M, Huebner G, Geissler RG, Heil G, Ganser A. Hepatic lesions of chronic disseminated systemic candidiasis in leukemia patients may become visible during neutropenia: value of serial ultrasound examinations. Blood 1998;91:3087-3089.

6. Pestalozzi BC, Krestin GP, Schanz U, Jacky E, Gmür J. Hepatic lesions of chronic disseminated candidiasis may become invisible during neutropenia. Blood 1997;90:3858-3864.

7. Bayram C, Fettah A, Yarali N, Kara A, Azik FM, Tavil B, Tunc B. Adjuvant corticosteroid therapy in hepatosplenic candidiasis-related iris. Mediterr J Hematol Infect Dis 2012;4:e2012018.

8. Conter $C D$, Thiesse $P$, Bienvenu A. Persistent fever and hepatosplenic candidiasis, efficiency of a corticoid therapy. J Mycol Med 2007;17:194197.

9. Chaussade H, Bastides F, Lissandre S, Blouin P, Bailly E, Chandenier J, Gyan E, Bernard L. Usefulness of corticosteroid therapy during chronic disseminated candidiasis: case reports and literature review. J Antimicrob Chemother 2012;67:1493-1495.

10. De Castro N, Mazoyer E, Porcher R, Raffoux E, Suarez F, Ribaud P, Lortholary O, Molina JM. Hepatosplenic candidiasis in the era of new antifungal drugs: a study in Paris 2000-2007. Clin Microbiol Infect 2012;18:185-187.

11. Saint-Faust M, Boyer C, Gari-Toussaint M, Deville A, Poiree M, Weintraub M, Sirvent N. Adjuvant corticosteroid therapy in 2 children with hepatosplenic candidiasis-related IRIS. J Pediatr Hematol Oncol 2009;31:794-796.

\title{
Posttranslational Modifications of Red Blood Cell Ghost Proteins as "Signatures" for Distinguishing between Low- and High-Risk Myelodysplastic Syndrome Patients
}

\author{
Düşük ve Yüksek Risk Miyelodisplastik Sendrom Hastalarını Ayıran "Işaretler" Olarak Kırmızı \\ Kan Hücre Zarı Proteinlerinin Posttranslasyonel Modifikasyonları
}

Klara Pecankova, Pavel Majek, Jaroslav Cermak, Jan E. Dyr

Institute of Hematology and Blood Transfusion, Prague, Czech Republic

To the Editor,

Myelodysplastic syndrome (MDS) comprises a heterogenic group of oncohematological diseases that affect hematopoiesis. Although the precise cause of MDS is unknown, multiple factors are involved, one of the most widely implicated of which is oxidative stress. However, it is unclear whether oxidative stress is a cause of MDS or an effect of other pathological mechanisms.

Red blood cells (RBCs) are the first cells exposed to stress stimuli. They are highly vulnerable to free radical accumulation, which leads to the oxidative stress that induces damage in proteins and 